\title{
Effect of Artificial Carbon Dioxide-Rich Water Immersion on Peripheral Blood Flow in Healthy Volunteers: Preliminary Study about Artificial Carbon Dioxide-Rich Water
}

\author{
Andi Rizky Arbaim Hasyar ${ }^{1 *}$ (D) , Haerani Rasyid² ${ }^{2}$, Irfan Idris ${ }^{3}$ (D), Irawan Yusuf ${ }^{3}$ D \\ ${ }^{1}$ Postgraduate Program, Faculty of Medicine, Universitas Hasanuddin, Makassar, Indonesia; ${ }^{2}$ Department of Internal Medicine, \\ Nephrology and Hypertension Division, Faculty of Medicine, Universitas Hasanuddin, Makassar, Indonesia; ${ }^{3}$ Department of \\ Physiology, Faculty of Medicine, Universitas Hasanuddin, Makassar, Indonesia
}

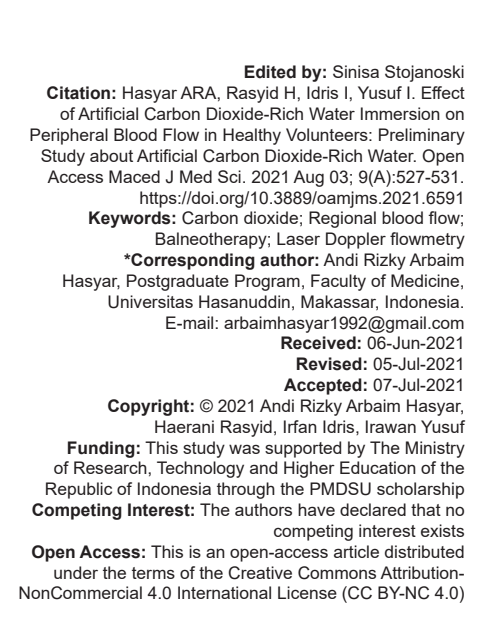

\begin{abstract}
BACKGROUND: Peripheral blood circulation disorder is one of the global health problems. Balneotherapy that uses $\mathrm{CO}_{2}$ springs may be one of the complementary treatment options. The device to produce artificial $\mathrm{CO}_{2}$-rich water is needed to achieve an improvement effect, at least almost like the improvement effect of natural balneotherapy.

AIM: This study aims to investigate the effect of artificial $\mathrm{CO}_{2}$-rich water immersion on peripheral blood flow using Bicarbonated JesC CREA BC-2000.

METHODS AND MATERIALS: Thirty-nine healthy volunteers participated in this study. Each subject immersed both of their legs in a mixed solution from water and $\mathrm{CO}_{2}$ at temperature $38^{\circ} \mathrm{C}$. This solution was mixed using a device namely, "Bicarbonated JesC CREA BC-2000". Peripheral blood flow was measured for 5 min before immersion (in this study, we denoted it as the mean basal blood flow), 10 min during immersion, and 5 min after immersion using pocket JMS laser Doppler flowmetry MBF-IIA. Repeated analysis of variance was used for statistical analysis.

RESULTS: There is the difference in peripheral blood flow among before, during, and after immersing the legs into
\end{abstract} artificial $\mathrm{CO}_{2}$-rich water using Bicarbonated JesC CREA BC-2000 $(p<0.001)$.

CONCLUSION: Bicarbonated JesC CREA BC-2000 may be used as the device to produce an artificial $\mathrm{CO}_{2}$-rich water bath that may affect peripheral blood flow in healthy volunteers.

\section{Introduction}

Balneotherapy, known as spa therapy, has been frequently and widely used in classical medicine to treat various diseases [1], [2], [3], [4]. The temperature of the water and the substances contained in the bath play an essential role in the beneficial effect of balneotherapy [3], [5]. The temperature of water is described as cold $\left(<20^{\circ} \mathrm{C}\right)$, hypothermal $\left(20-30^{\circ} \mathrm{C}\right)$, thermal $\left(>30-40^{\circ} \mathrm{C}\right)$, or hyperthermal $\left(>40^{\circ} \mathrm{C}\right)$ [1], [4]. Moreover, natural gas, such as carbon dioxide $\left(\mathrm{CO}_{2}\right)$, is one of the substances used for balneotherapy [3], [6], [7]. Both $\mathrm{CO}_{2}$ [8], [9] and heat [2], [10] have been recognized as triggering factors for vasodilation.

In some regions of Europe, balneotherapy has been linked with the use of $\mathrm{CO}_{2}$ spring. Balneotherapy by $\mathrm{CO}_{2}$ spring has been believed to be beneficial in treating hypertension, cardiovascular disorders, and peripheral occlusive arterial disease [5], [6], [7]. The $\mathrm{CO}_{2}$ spring itself is defined as spring water originating naturally or dug and contains a minimum of $1000 \mathrm{mg} / \mathrm{kg}$ of free $\mathrm{CO}_{2}$ [5], [11]. In some areas, it is quite challenging to find a $\mathrm{CO}_{2}$ spring as defined. To identify the effect of $\mathrm{CO}_{2}$ immersion, artificial $\mathrm{CO}_{2}$-enriched water had been prepared by various methods, such as $\mathrm{CO}_{2}$ gas that bubbled into bathwater or tablets containing $\mathrm{CO}_{2}$ dissolved in water [5], [8], [11]. However, it is challenging to maintain $\mathrm{CO}_{2}$ concentrations above $1000 \mathrm{ppm}$ for several hours with these methods.

Recently, the device has been modified to obtain the artificial $\mathrm{CO}_{2}$ water bath efficiently and according to the previously developed definition of $\mathrm{CO}_{2}$ spring, either through the use of special membranes (doublelayered composite perforated fiber membranes) or a spa maker with ordinary tap water and high-pressure $\mathrm{CO}_{2}$ from gas cylinders [5], [8], [9]. On the other hand, the use of devices that produce bicarbonate water for therapy is still relatively new in some region of Indonesia. While, such devices have developed in developed countries, including Japan [8],[12],[13]. Unfortunately, the research about the effects of artificial $\mathrm{CO}_{2}$-rich water and a suitable device for producing artificial $\mathrm{CO}_{2}$-rich water with an improvement effect 
like natural spring balneotherapy is still lacking. Therefore, in this preliminary study, we tried to test the effectiveness of Bicarbonated JesC CREA BC-2000, a high concentration hydrogen carbonate ion spring with a maximum performance of $1300 \mathrm{ppm}$, in producing artificial $\mathrm{CO}_{2}$-rich water, which is hypothesized that can improve peripheral circulation.

\section{Methods}

\section{Design study}

This is a pre-experimental research with the one-group pre-test-post-test design. There was no a control group in this study. While, the research process was carried out with three measurements of peripheral blood flow. They are before, during, and after immersion of the legs in artificial $\mathrm{CO}_{2}$-rich water bath.

\section{Population and study setting}

\section{Subjects and data collection}

In this preliminary study, we investigated the effect of using artificial $\mathrm{CO}_{2}$-rich water on changes in blood flow in healthy volunteers. There were 53 volunteers who participated in this study, but only 39 people met our inclusion criteria. Before conducting the experiment, each volunteer was asked to answer several questions related to their medical histories, both the presence of diabetes and the presence of other cardiovascular diseases. Then, observations were made regarding the presence or absence of wounds on the legs, and blood pressure was also checked using a sphygmomanometer. Volunteers with hypertension (>140 mmHg), leg injuries, and admitting a history of cardiovascular disease or diabetes mellitus were excluded from the study. Thus, at the end of the observation, 39 samples were obtained in this study. Each subject signed an informed consent. All experiments were carried out at Hasanuddin University Medical Research Center at $6^{\text {th }}$ floor of the Hasanuddin University Hospital.

\section{The protocol of $\mathrm{CO}_{2}$-rich water bathing and blood flow measurement}

Peripheral blood flow was measured using a non-invasive measurement method that shows the value of every second by the pocket laser Doppler flowmetry MBF-IIA series (JMS, Hiroshima, Japan). This device has a sensor pad set on the dorsal left foot between the first and second finger of each subject. The data of the peripheral blood flow were stored in the pocket laser Doppler flowmetry software (version 1.02, Japan). The mean value of every minute was calculated using Microsoft Excel 2010. All the data were shown on a personal computer (Toshiba, Tokyo, Japan). The measurements were made for 5 min before immersion, 10 min during immersion, and 5 min after immersion, respectively.

During the experiment, before measurement of peripheral blood flow, subjects were asked to sit without shoes and socks. None of the subjects wore tight pants that might affect the blood flow in the legs, so before doing the immersion, we only asked them to lift the pants/skirt above their knees. They were instructed, not to talk or move during the measurement. Each subject was asked to immerse both legs under their knees into a container with artificial $\mathrm{CO}_{2}$-rich water, an output that comes out of a highly concentrated hydrogen carbonate ion spring (Bicarbonated CREA BC-2000, JesC, Nagoya, Japan) as a device for obtaining $\mathrm{CO}_{2}$ rich water with maximum concentrations 1300 ppm. This device was connected to a water heater (Ariston, TI-SHAPE 15 OR 500 ID, Marche, Italy), which was set at temperature of $38^{\circ} \mathrm{C}$, as a warm water source and a gas cylinder containing $\mathrm{CO}_{2}$ as a $\mathrm{CO}_{2}$ source. After the artificial $\mathrm{CO}_{2}$-rich water comes out, the temperature is measured again with a mercury thermometer to ensure that the output temperature is $38^{\circ} \mathrm{C}$. While, the $\mathrm{pH}$ of this output was measured by a $\mathrm{pH}$ meter (Sato, SK-620PH II, China), with its range between 4.5 and 5.6 .

\section{Data analysis}

To record the difference of the peripheral blood flow before, during, and after immersing the legs in $\mathrm{CO}_{2}$-rich water, repeated analysis of variance (ANOVA) was used. The data (mean \pm Std. deviation) were considered significant at $p<0.05$ and were calculated using the SPSS 16.0.

\section{Ethical aspect}

The Ethics Committee Health Research in the Medical Faculty of the Hasanuddin University approved this experimental protocol with Letter No 387/ H4.8.4.5.31/PP36-KOMETIK/2018.

\section{Results}

\section{Characteristics of the subjects}

The characteristics of the respondents are shown in Table 1. Thirty-nine respondents were enrolled in this study, consisted of $53.8 \%$ of male, and $46.2 \%$ of female. The mean age of the subjects was $32.90 \pm 13.613$ years. The mean body mass index was $23.98 \pm 5.066 \mathrm{~kg} / \mathrm{m}^{2}$, which indicates that 
Table 1: Demographic characteristics of respondents

\begin{tabular}{ll}
\hline Parameter & Frequency $(\mathrm{n}=39)$ \\
\hline${ }^{\mathrm{a}} \mathrm{Sex}$ & \\
Male & $21(53.8)$ \\
Female & $18(46.2)$ \\
${ }^{\mathrm{b}} \mathrm{Ages}(\mathrm{years})$ & $32.90 \pm 13.613$ \\
${ }^{\mathrm{b}} \mathrm{BMI}\left(\mathrm{kg} / \mathrm{m}^{2}\right)$ & $23.98 \pm 5.066$ \\
${ }^{\mathrm{b}} \mathrm{SBP}(\mathrm{mmHg})$ & $114.21 \pm 10.270$ \\
${ }^{\mathrm{b}} \mathrm{DBP}(\mathrm{mmHg})$ & $74.31 \pm 8.234$ \\
\hline N: Number of subjects; SBP: Systolic blood pressure; DBP: Diastolic blood pressure; BMI: Body mass \\
index. ${ }^{\mathrm{a} P a r a m e t e r s ~ w i t h ~ c a t e g o r i c a l ~ d a t a, ~ v a l u e s ~ a r e ~ e x p r e s s e d ~ a s ~} \mathrm{n}(\%) .{ }^{\mathrm{b}}$ Parameters with numerical data, \\
values are expressed as mean $\pm \mathrm{SD}$.
\end{tabular}

the subjects in this study had a body mass index in the normal category. Furthermore, the mean blood pressure of all respondents was in the normal category, namely, $114.21 \pm 10.270$ and $74.31 \pm$ $8.234 \mathrm{mmHg}$ for systolic blood flow and diastolic blood flow, respectively.

\section{Association between Artificial $\mathrm{CO}_{2}-$ rich water immersion and the peripheral blood flow}

Using repeated measurement ANOVA test, it was found that there was a significant difference between mean basal blood flow, mean blood flow during legs immersion in $\mathrm{CO}_{2}$-rich water bath, and mean blood flow after legs immersion ( $p=0.000$, Table 2$)$.

Table 2: Peripheral blood flow in different conditions

\begin{tabular}{lll}
\hline Condition & Mean \pm Std. deviation $(\mathrm{mL} / \mathrm{min})$ & $\mathrm{p}$-value \\
\hline Blood flow before $\mathrm{CO}_{2}$-rich water immersion & $4.34 \pm 0.166$ & $<0.001$ \\
Blood flow during $\mathrm{CO}_{2}$-rich water immersion & $6.57 \pm 0,272$ & \\
Blood flow after $\mathrm{CO}_{2}$-rich water immersion & $4.72 \pm 0.159$ & \\
\hline $\mathrm{CO}_{2}$ : Carbon dioxide. & &
\end{tabular}

It appears that the value of mean peripheral blood flow increased during the legs immersion in $\mathrm{CO}_{2}$-rich water of the basal value and then decreased after immersion, with the value that was close to the basal mean blood flow (Figure 1).

Based on the Bonferroni test that is shown in Table 3, it was found that peripheral blood flow during immersion was significantly different from basal blood flow and blood flow after immersion (respectively, $p=0.000$ and $p=0.000$ ). However, there was no significant difference between basal blood flow and blood flow after immersion $(p=0.092)$.

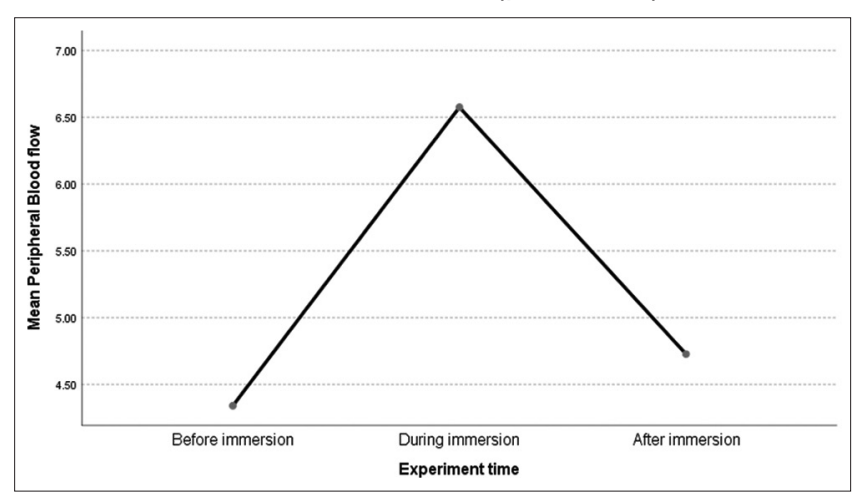

Figure 1: Graph of mean peripheral blood flow: Before exposed to $\mathrm{CO}_{2}$-rich water immersion, during exposed to $\mathrm{CO}_{2}$-rich water immersion, and after exposed to $\mathrm{CO}_{2}$-rich water
Table 3: Pairwise comparison of mean peripheral blood flow

\begin{tabular}{llll}
\hline Condition & Comparison condition & Mean difference & Sig. \\
\hline Before immersion & During immersion & $-2.23^{*}$ & $<0.001$ \\
& After immersion & -0.38 & 0.092 \\
During immersion & Before immersion & $2.23^{*}$ & $<0.001$ \\
& After immersion & $1.84^{*}$ & $<0.001$ \\
After immersion & Before immersion & 0.38 & 0.092 \\
& During immersion & $-1.84^{*}$ & $<0.001$ \\
\hline Asterisk (*) indicates that the mean difference is significant at the 0.05 level; b, adjustment for multiple \\
comparisons: Bonferroni.
\end{tabular}

\section{Correlation of the respondent} characteristics and the peripheral blood flow during legs immersion in artificial $\mathrm{CO}_{2}$-rich water bath

In this study, to ensure that this increase in peripheral blood flow was purely influenced by artificial $\mathrm{CO}_{2}$-rich warm water, multivariate analysis was performed. This multivariate analysis by linear regression test shows no correlation between sex, age, body mass index, systolic blood pressure (SBP), or diastolic blood pressure (DBP) on changes in peripheral blood flow during immersion of the legs in artificial $\mathrm{CO}_{2}$ rich warm water (Table 4).

Table 4: Linear regression analysis of characteristics respondents related to peripheral blood flow during immersion

\begin{tabular}{llll}
\hline Demographic characteristics of respondents & Coefficient & Standard error & p-value \\
\hline Sex & 1.058 & 0.730 & 0.158 \\
Ages (years) & 0.035 & 0.023 & 0.143 \\
BMI $\left(\mathrm{kg} / \mathrm{m}^{2}\right)$ & -0.059 & 0.096 & 0.546 \\
SBP $(\mathrm{mmHg})$ & -0.007 & 0.044 & 0.871 \\
DBP $(\mathrm{mmHg})$ & 0.012 & 0.051 & 0.808 \\
\hline
\end{tabular}

SBP: Systolic blood pressure; DBP: Diastolic blood pressure; BMI: Body mass index

\section{Discussion}

This pre-experimental design study found an increase in peripheral blood flow during legs immersion into artificial $\mathrm{CO}_{2}$-rich water from the basal control value before immersion in healthy volunteers. Furthermore, after the legs were removed from the immersion, the peripheral blood flow during the immersion decreases almost near the basal peripheral blood flow value. Thus, it suggests that artificial $\mathrm{CO}_{2}$-rich water immersion may affect peripheral blood flow in healthy volunteers. Meanwhile, the decrease in blood flow after the legs is removed from the bath, close to the basal blood flow value, may be because the changes in environmental temperature by bathing affect the expansion and contraction of blood vessels through the autonomic system [12].

The results of this study are in line with the research of Nishimura et al. (2002) which showed an increase in cutaneous blood flow in the forearm reaching 200-250\% during bathing in carbon dioxide-rich water from the control value before bathing and tended to decrease after leaving out of the tub [8]. Similarly, the research of Ogoh et al. (2018) showed an increase in popliteal artery blood flow for 20 min of immersing the leg in warm carbonated water [14]. Furthermore, Watanabe 
et al. (2006) showed three peaks of changes in peripheral blood flow associated with bathing in inorganic salts and carbon dioxide, the first occurred shortly after the start of immersion, the second occurred just before the end of immersion, and the third occurred after immersion [12]. In addition, animal studies have shown that repeated carbonated water immersion enhances angiogenesis and muscle blood flow in ischemic limbs [15]. Thus, these studies indicate that $\mathrm{CO}_{2}$-rich water has a beneficial effect on peripheral circulation improvement, especially when administered repeatedly. It should be noted, these studies in human subjects also used artificial $\mathrm{CO}_{2}$-rich water baths. Although these studies used the device to produce artificial $\mathrm{CO}_{2}$-rich water and the blood flow measurement device was different from this study, the peripheral blood flow improvement was almost the same as our results. That way, not only natural $\mathrm{CO}_{2}$ springs but artificial $\mathrm{CO}_{2}$-rich water may also produce beneficial effects for the body. Therefore, these results indicate that the device used for mixing the $\mathrm{CO}_{2}$ and warm water in this study may be considered to produce artificial $\mathrm{CO}_{2}$-rich water that is beneficial for the body. In addition, the use of the blood flow meter that we use may also be considered to be used in further research related to peripheral blood flow measurement.

Balneotherapy or spa therapy has been used for long time in classical medicine. It also has been believed to have benefit in body health. Over the past few decades, this kind of therapy has played an essential role in the treatment for many diseases, such as; hypertension, cardiovascular disorders, and peripheral occlusive arterial diseases; the mechanical effect is obtained from hydrostatic pressure, where immersion allows the patient to mobilize joints and strengthen muscles with minimal discomfort, also causes fluid transfer from the extremities to the trunk, resulting in hemodilution and increased diuresis; thermal effects caused by high-temperature water may cause superficial vasodilation; the chemical effect is obtained through various spa water compositions and physical properties (such as salty, sulfurous, bicarbonate, carbonic, radon rich, selenium rich, arsenical, and ferruginous) [1]. In this study, we mix the $\mathrm{CO}_{2}$ in $38^{\circ} \mathrm{C}$ water, which allows for both thermal and chemical effects. Both $\mathrm{CO}_{2}$ [8], [9] and heat [2], [10] have been recognized as triggering factors for vasodilation. Thus, the artificial $\mathrm{CO}_{2}$-rich water in this study may increase the blood flow through the vasodilation mechanism produced by the combination of warm water and $\mathrm{CO}_{2}$.

In some European regions, balneotherapy is carried out using $\mathrm{CO}_{2}$ springs, defined as springs originating naturally or dug and containing minimum concentrations of $1000 \mathrm{mg} / \mathrm{kg}$ of free $\mathrm{CO}_{2}$ [5], [14]. In addition, for its result effectiveness in flow-mediated vasodilation, the water spa temperature is generally thermal [3], [14], [10]. Indeed, it had been known that water is a good conductor of heat [16], high temperatures can cause vasodilation [2], [10], and $\mathrm{CO}_{2}$ is a powerful vasodilator [8], [9]. Recently, the device has been modified to obtain the artificial $\mathrm{CO} 2$ water bath efficiently and according to the previously developed definition of $\mathrm{CO}_{2}$ spring, either through the use of special membranes (double-layered composite perforated fiber membranes) or a spa maker with ordinary tap water and high-pressure $\mathrm{CO}_{2}$ from gas cylinders [5], [8], [9]. In this study, we used Bicarbonated JesC CREA BC-2000, a device with a special membrane (multilayer composite fiber membrane), to obtain $\mathrm{CO}_{2}$-rich water with a maximum $\mathrm{CO}_{2}$ concentration of $1300 \mathrm{ppm}$. Thus, this device makes it possible to produce artificial $\mathrm{CO}_{2}$ rich water that can affect peripheral blood flow.

The results of multivariate analysis in this study showed that gender, age, body mass index, basal SBP, and DBP did not affect the change of peripheral blood flow during immersion. It suggests that artificial $\mathrm{CO}_{2}$ rich water was responsible for the changes in blood flow in this study. In other words, gender, age, body mass index, and basal SBP and DBP were not confounding factors in changes in peripheral blood flow during the legs were immersed in $\mathrm{CO}_{2}$-rich water in this study.

Finally, it should be mentioned that this study has a particular limitation, such as the inability to elucidate the physiological mechanisms associated with vasodilation by artificial $\mathrm{CO}_{2}$-rich water produced by the device used in this study. It happened because this our preliminary study, we did not measure blood samples on the research subject. It is hoped that in future research, this mechanism will become clear. Therefore, future studies regarding blood sample investigations and factors involved in vasodilation may be more interesting.

\section{Conclusion}

This study noted that the use of Bicarbonated JesC CREA BC-2000 produced artificial $\mathrm{CO}_{2}$-rich water that might increase peripheral arterial blood flow during immersion, and decreased after immersion to a value close to basal blood flow. Therefore, it is drawn that the device we use can be considered to produce artificial $\mathrm{CO}_{2}$-rich water that produces beneficial effects on health. Unfortunately, in this study, we have not analyzed the blood plasma of the study subjects to find the vasodilation mechanism that might be the cause of the increase in blood flow. This kind of investigation is needed in future studies.

\section{Acknowledgment}

This research was funded by The Ministry of Research, Technology and Higher Education of the 
Republic of Indonesia through the PMDSU scholarship (research grant No. 4514/UN4.21/PL.00.00/2018). We also would like to thank Kaikoukai Healthcare Group, Japan, for contributing to procurement of bicarbonated JesC CREA BC-2000 that we used in this study.

\section{References}

1. Nasermoaddeli A, Sadanobu K. Balneotherapy in Medicine: A review. Environ Health Prev Med. 2005;10(4):171-9. https:// doi.org/10.1007/bf02897707

PMid:21432136

2. Dandinoglu T, Dandin O, Ergin T, Tihan D, Akpak YK, Aydın OU, et al. Can balneotherapy improve the bowel motility in chronically constipated middle-aged and elderly patients? Int J Biometeorol. 2017;61(6):1139-48. https://doi.org/10.1007/ s00484-016-1295-8

PMid:28011998

3. Gálvez I, Torres-Piles S, Ortega-Rincón E. Balneotherapy, immune system, and stress response: A hormetic strategy? Int J Mol Sci. 2018;19(6):1687. https://doi.org/10.3390/ijms19061687 PMid:29882782

4. Huang A, Seité S, Adar T. The use of balneotherapy in dermatology. Clin Dermatol. 2018;36(3):363-8. PMid:29908578

5. Pagourelias E, Zorou PG, Tsaligopoulos M, Athyros VG, Karagiannis A, Efthimiadis GK. Carbon dioxide balneotherapy and cardiovascular disease. Int J Biometeorol. 2010;55(5):657-63. https://doi.org/10.1007/s00484-010-0380-7 PMid:20967468

6. Dogaru G, Bulboaca A, Stanescu I, Rus V, Gyorgy B, Ciumarnean $\mathrm{L}$, et al. The effect of carbonated natural mineral water on oxidative stress in experimental myocardial ischemia. Rev Chim. 2019;70(7):2677-80. https://doi.org/10.37358/ rc. 19.7.7404

7. Rühle PF, Klein G, Rung T, Tiep Phan H, Fournier C, Fietkau R, et al. Impact of radon and combinatory radon/carbon dioxide spa on pain and hypertension: Results from the explorative RAD-ON01 study. Mod Rheumatol. 2019;29(1):165-72. https:// doi.org/10.1080/14397595.2018.1442640

PMid:29451048
8. Nishimura N, Sugenoya J, Matsumoto T, Kato M, Sakakibara H, Nishiyama T, et al. Effects of repeated carbon dioxide-rich water bathing on core temperature, cutaneous blood flow and thermal sensation. Eur J Appl Physiol. 2002;87(4-5):337-42. https://doi. org/10.1007/s00421-002-0626-0

\section{PMid:12172871}

9. Xu YJ, Elimban V, Dhalla NS. Carbon dioxide water-bath treatment augments peripheral blood flow through the development of angiogenesis. Can J Physiol Pharmacol. 2017;95(8):938-44. https://doi.org/10.1139/cjpp-2017-0125 PMid:28704614

10. Inoue S, Takemoto M, Chishaki A, Ide T, Nishizaka M, Miyazono $\mathrm{M}$, et al. Leg heating using far infra-red radiation in patients with chronic heart failure acutely improves the hemodynamics, vascular endothelial function, and oxidative stress. Intern Med. 2012;51(17):2263-70. https://doi. org/10.2169/internalmedicine.51.7115

PMid:22975533

11. Ogoh $S$, Nagaoka $R$, Mizuno $T$, Kimura $S$, Shidahara $Y$, Ishii $\mathrm{T}$, et al. Acute vascular effects of carbonated warm water lower leg immersion in healthy young adults. Physiol Rep. 2016;4(23):e13046. https://doi.org/10.14814/phy2.13046 PMid:27923974

12. Watanabe $\mathrm{S}$, Imanishi $\mathrm{N}$, Ishizawa $\mathrm{T}$, Yano $\mathrm{S}$, Takeda $\mathrm{S}$, Miyamoto $\mathrm{K}$, et al. The effects of bathing with inorganic salts and carbon dioxide on body temperature, systemic circulation, and food ingestion and absorption. J Japanese Soc Balneol Climatol Phys Med. 2006;69(3):167-78.

13. Matsuo H, Hayashi T, Takeda Y, Tsuji T, Endo H, Shinohara T. The effects of artificial carbon dioxide foot bathing on the skin of ischemic feet measured by laser doppler flowmeter. J Japanese Coll Angiol. 2000;40(11):923-8.

14. Ogoh S, Washio T, Suzuki K, Ikeda K, Hori T, Olesen ND, et al. Effect of leg immersion in mild warm carbonated water on skin and muscle blood flow. Physiol Rep. 2018;6(18):e13859. https:// doi.org/10.14814/phy2.13859 PMid:30221833

15. Irie H, Tatsumi T, Takamiya M, Zen K, Takahashi T, Azuma A et al. Carbon dioxide-rich water bathing enhances collateral blood flow in ischemic hindlimb via mobilization of endothelial progenitor cells and activation of NO-cGMP system. Circulation. 2005;111(12):1523-9. https://doi.org/10.1161/01. cir.0000159329.40098.66 PMid:15795362

16. Alexiou $\mathrm{S}$. The effect of water temperature on the human body and the swimming effort. J Biol Exerc. 2014;10(2):9-23. 